\title{
Long-Term Effects of Mild Oligonephronia Induced In Utero by Gentamicin in the Rat ${ }^{1}$
}

\author{
THIERRY GILBERT, MARTINE LELIEVRE-PEGORIER, AND CLAUDIE MERLET-BENICHOU
}

Unité de Recherches sur le Développement Normal et Pathologique des Fonctions Epithéliales, INSERM U 319 , Université Paris 7, Paris, France

\begin{abstract}
Renal clearance studies and morphologic observations were performed in rats aged 14,21 , and $28 \mathrm{~d}$ and $3,6,9$, and 12 mo born with a $20 \%$ reduction in nephron number after administration of $75 \mathrm{mg} / \mathrm{kg} / \mathrm{d}$ of gentamicin to their mothers during the second half of gestation. Gentamicin was still present in urine 3 mo after birth. Morphologic damage characteristic of gentamicin accumulation was observed in the kidney on $\mathrm{d} 14$ and 21 . Adequate compensatory adaptation to oligonephronia occurred for glomerular function within $14 \mathrm{~d}$ of birth, but tubular phosphate reabsorption was significantly low on $d$ 21. On d 28, no evidence of histologic or functional damage to the kidney was observed. At 3 mo, mesangial lesions were observed in rats of the gentamicin group, whereas they were rarely present in 6-mo-old control rats. Furthermore, glomerular sclerotic lesions were already evident in about $5 \%$ of the juxtamedullary nephrons. The same percentage of injured nephrons was not observed before 12 mo in controls. Complementary morphologic data obtained in 24-mo-old rats showed that glomerulosclerosis involved $40 \%$ of the juxtamedullary nephron population at this age in animals of the gentamicin group versus $21 \%$ in controls. It is concluded that in the young rats born with oligonephronia of gentamicin-treated mothers neither the gentamicin remaining in the kidney cells nor the injuries it caused them prevented compensatory adaptation of the kidney to a reduced number of nephrons. However, although this oligonephronia was mild, it might have been sufficient to cause early development of glomerular sclerosis in the adults. (Pediatr Res 30: 450-456, 1991)
\end{abstract}

Abbreviations

GFR, glomerular filtration rate

The effect of in utero exposure to aminoglycoside antibiotics like gentamicin on the developing kidney has aroused increasing interest during the past few years (1-5). Prolonged administration of gentamicin to pregnant rats during the second half of gestation was reported to cause mild but significant oligonephronia, which reduced the number of nephrons normally present at birth by about $20 \%(1,3)$. Nephrogenesis is known to continue after birth in the rat (6). It did so in rats born of gentamicin-treated mothers, but the nephron deficit was not made up, so that the final number of nephrons was still significantly below normal (3). Of interest

Received November 20, 1990; accepted April 15, 1991.

Correspondence: Dr C. Merlet-Bénichou, INSERM U319, Université Paris 7, 2 , place Jussieu, 75251 Paris, France.

Part of this work appeared in abstract form in the proceedings of the 3rd International Symposium on Nephrotoxicity, Guilford, England, 1987, and of the 1st Congress of the European Society for Developmental Pharmacology, Les Diabblerets, Switzerland, 1988. was the fact that nephrogenesis was deficient at a concentration of gentamicin in the kidney lower than that measured in the kidney of human fetuses after a single injection of aminoglycosides to their mothers $(3,7,8)$. Furthermore, in rats born of gentamicin-treated mothers, we observed extensive damage of the most mature nephrons resembling that described in the kidney of adult rat exposed to gentamicin, as well as focal ultrastructural lesions in the subcapsular nephrogenic zone (4).

It has long been established that a reduction of renal mass is followed by compensatory hypertrophy and hyperfunction of the remaining nephrons. This compensatory adaptation to nephron loss was found to be age-dependent; the earlier the nephron loss, the greater the compensation (9-12). There is also substantial evidence that, after renal mass ablation, the hyperfunctioning of the remaining nephrons, which at first appears beneficial, in fact has a harmful long-term effect because it accelerates the development of glomerular sclerosis (for review see Ref. 13). Glomerular sclerosis has been reported to develop in children born with a reduced number of nephrons $(14,15)$ and in patients with unilateral renal agenesis (16-18). One of these reports indicates that the incidence of glomerular sclerosis might be higher when renal mass reduction occurs in utero than at the adult stage (18). In addition, inborn deficits in nephron number are believed to be involved in the observed differences in susceptibility to hypertension that characterize different human populations (19). Such deficits may also contribute to susceptibility to development of renal disease in patients with diabetes mellitus (19). Long-term studies of compensatory renal adaptation in animals undergoing nephron loss in infancy are still rare $(11,20)$, and no animal model of acquired oligonephronia in utero has yet been investigated. Lastly, experimental studies of the long-term consequences of renal compensatory adaptation to nephron loss, whatever the animal's age at the time of this loss, were performed after ablation of at least half the renal mass. Consequently, it is still not known how large a reduction in nephron mass is necessary to initiate progressive renal disease (13).

The present study was therefore designed to establish 1) whether, in animals born of gentamicin-treated mothers, the kidney is able not only to reach maturity, but also to compensate for the oligonephronia acquired in utero, despite the morphologic damage caused by gentamicin and the fact that some gentamicin remains in the kidney; and 2) whether the mild oligonephronia acquired in utero might be sufficient to result in premature glomerular sclerosis in the adult.

\section{MATERIALS AND METHODS}

Animals. Fifteen pregnant Sprague-Dawley rats of known mating dates received a daily intramuscular injection of $75 \mathrm{mg} \cdot \mathrm{kg}^{-1}$ gentamicin in saline, for $12 \mathrm{~d}$, from the 10th $\mathrm{d}$ of gestation to term. Another group of 10 pregnant rats received an equivalent volume of saline during the same period of gestation. The rats were allowed to deliver spontaneously. All litters were randomly reduced to eight pups, which were separated from their mothers 
3 wk after birth. All animals had free access to tap water and a standard laboratory diet containing $22 \%$ proteins (A03; UAR, Epinay sur Orge, France).

Clearance studies. Clearance experiments were carried out on male rats issued from saline or gentamicin-treated mothers at the ages of 14,21 , and $28 \mathrm{~d}$, and 3, 6, 9, and $12 \mathrm{mo}$. The animals were anesthetized with $10 \mathrm{mg} \cdot 100 \mathrm{~g}^{-1}$ Inactin (Byk Gulden Pharmaceuticals, Konstanz, Germany) injected intraperitoneally. They were then placed on a heated table to maintain their body temperature at $38^{\circ} \mathrm{C}$, and tracheotomy was performed. An external jugular vein and a femoral artery were catheterized for infusion and blood collection, respectively (polyethylene catheters, PE-10 or PE-50; Intramedic, Clay Adams, Parsippany, NJ). Another catheter was inserted in each ureter for urine collection. After surgery, arterial blood pressure was measured and the animals were infused with isotonic saline (1.3\% of body weight). They were then given a priming dose of $16 \mathrm{kBq}$ of $\left[{ }^{3} \mathrm{H}\right]$ methoxy inulin per $100 \mathrm{~g}$ (sp act, $16.3 \mathrm{mBq} / \mathrm{mg}$; New England Nuclear Corp.; Boston, MA), followed by an appropriate sustaining dose of this labeled molecule in saline, administered at a rate of 10 $\mu \mathrm{L} / \mathrm{min} / 100 \mathrm{~g}$, which maintained the animal in normal diuresis throughout the experiment. Urine was collected $60 \mathrm{~min}$ after the priming dose and for three periods of 10 to $45 \mathrm{~min}$ each, according to the age of the animal. Arterial blood samples were taken during each period. Blood samples were immediately centrifuged, and the plasma was stored for analysis. In animals less than 1 mo of age, the erythrocytes were reinjected after addition of saline. In the plasma and urine samples, the concentration of $\left[{ }^{3} \mathrm{H}\right]$ methoxy inulin was determined with a liquid scintillation counter (LKB Instruments, Inc., Rockville, MD) in Instagel solution (Packard Instruments Co., Inc., Rockville, MD). Osmotic pressure was measured by a vapor pressure osmometer (Wescor Inc., Logan, UT). The phosphate concentration was measured by the method of Chen et al. (21). In plasma and urine samples from 1- to 12-mo-old animals, the sodium, potassium, magnesium, and calcium concentrations were determined with an atomic fluorescence spectrometer (Baird, Bedford, MA).

The 3- to 12-mo-old rats were placed in metabolic cages for $48 \mathrm{~h}$ before clearance experiments, and proteinuria was measured in the second 24-h urine sample by the biuret method using an autoanalyzer (Instrumentation Laboratory System 508, Wilmington, MA). In the urine of 3-mo-old animals in the gentamicin group, RIA of gentamicin was performed as previously described (22).

Morphologic studies. At the end of the clearance experiments, both kidneys were removed and weighed. In the left kidney, the number of nephrons was determined by the method of Damadian et al. (23). In the 14-d-old rats, half of the right kidney was prepared for determination of proximal tubular length by maceration followed by microdissection, as described previously (24). In all animals, the right kidney was processed for light microscopy: a medium slice was cut parallel to the kidney short axis and immersed in Dubosq-Brazil solution. After dehydration and embedding in paraffin-Paraplast (Monoject, Kildane, Ireland), $2-\mu \mathrm{m}$ sections were cut and stained with Masson's trichrome, with the periodic acid-Schiff reaction, or with Jones' reticulin staining. Nonserial cross-sections of the entire kidney were used to determine glomerular volume and for histologic observations.

Glomerular volume was measured using a system based on computer analysis of a hand-drawn picture superposed on the video image. For each animal, 20 superficial and 10 juxtamedullary glomeruli were selected. The surface area of the glomerular profile was measured by tracing a perimeter along the capsular basement membrane and the corresponding glomerular volume estimated assuming that the glomerulus was a sphere. The criteria retained to select a glomeruius cut near the equatorial plane were the following: 1 ) presence of the vascular pole (afferent and/or efferent arteriola); 2) connection of the proximal convoluted tubule with the glomerular urinary space; and 3) absence of a continuous urinary space around the glomerular tuft. About $6 \%$ of the total glomerular profiles present in a full kidney section fulfilled these conditions. The selection was made without knowledge of the origin of the section, and it was assumed that vascular and tubular poles were facing one another.

Semiquantitative histologic analysis of the glomerular and tubular injuries was done in a double-blind study and performed in 3- to 12-mo-old animals used for clearance experiments and in an additional group of approximately 24 -mo-old rats comprising three animals issued from the gentamicin group whose kidneys were removed post-mortem and three control animals. For the glomerular findings, the presence and the severity of glomerulosclerosis was evaluated by examining 30 superficial and 20 juxtamedullary glomeruli for each animal. Glomeruli were graded from 0 to 3: 0 for absence of lesions; 1 for a mild increase in the mesangial matrix with some deposits; 2 for segmental sclerotic lesion and some capillary lumen obliteration; and 3 for sclerosis involving half of the glomerulus with adhesion between the tuft and the capsule. With regard to tubular injuries, the presence of cytoplasmic inclusions was evaluated. The intensity and extent of this lesion were also graded from 0 to 3 . The presence of casts in the tubular lumina was noted.

Statistics. All values are reported as means \pm SEM. Intergroup significance was calculated using variance analysis. Relationships between two parameters were calculated by determining Pearson's correlation coefficient.

\section{RESULTS}

In rats born of gentamicin-treated mothers, body and kidney weights were the same as those of control animals of the corresponding age (Table 1). All the control animals had more than 31000 nephrons. In animals born of gentamicin-treated mothers, the mean number of nephrons was significantly lower at all ages studied. Three out of the 45 rats of this group had more than 31000 nephrons; data obtained in these rats are reported separately.

Functional data. Plasma concentrations for sodium, potassium, magnesium, calcium, phosphate, and total solutes were not different in the gentamicin and control groups. Arterial blood pressure increased with age until $3 \mathrm{mo}$; it was the same in both groups at all ages. Table 1 shows that, already at $14 \mathrm{~d}$, the GFR were identical in the gentamicin and control groups and rose until the age of $3 \mathrm{mo}$. From 3 to $12 \mathrm{mo}$, the GFR continued to increase slightly in the controls $(y=99 x+1150, r=0.86, p<$ $0.001, n=21$ ) but not in the animals issued from gentamicintreated mothers (Table 1). GFR per $100 \mathrm{~g}$ body weight remained stable from 3 mo onward in controls, but dropped significantly in the gentamicin group $(y=-14 x+431, r=0.62, p<0.01, n$ $=23$ ). Neither the flow rate of urine nor its osmolarity were significantly different at any age in the two groups.

Fractional water and electrolyte excretion did not differ in animals born of gentamicin-treated or control mothers, except for phosphate. As shown in Figure 1, phosphate excretion was relatively high and not different in both groups on d 14; however, by $\mathrm{d} 21$, it had significantly dropped in controls but remained high in the gentamicin group. At $28 \mathrm{~d}$ and $3 \mathrm{mo}$, phosphate excretion was significantly lower in the gentamicin group. Maturational changes in phosphate fractional excretion for the first 3 mo were in fact about the same in the gentamicin and control groups, but occurred later in the gentamicin group. From $3 \mathrm{mo}$ onward, fractional excretion of phosphate rose in this group.

In 3-mo-old animals, proteinuria was present in both groups, but was significantly lower in the gentamicin group (Table 2). At 6 and $9 \mathrm{mo}$, it was not different in both groups and, at $12 \mathrm{mo}$, it was significantly higher in the gentamicin group.

At $3 \mathrm{mo}$, animals exposed in utero to gentamicin were still excreting this antibiotic. Its concentration measured in 24-h urine samples was $8.9 \pm 2.4 \mathrm{ng} / \mathrm{mL}(n=5)$.

Morphologic data. At all ages, glomerular volume was signifi- 
Table 1. Body and kidney weights, number of nephrons, and GFR per kidney in rats born of control and gentamicin-treated mothers

\begin{tabular}{|c|c|c|c|c|}
\hline $\begin{array}{c}\text { Age and } \\
\text { treatment group }\end{array}$ & $\begin{array}{c}\text { Body wt } \\
(\mathrm{g})\end{array}$ & $\begin{array}{c}\text { Kidney wt } \\
(\mathrm{mg})\end{array}$ & $\begin{array}{l}\text { Number of } \\
\text { glomeruli }\end{array}$ & $\begin{array}{c}\text { GFR/kidney } \\
(\mu \mathrm{L} / \mathrm{min})\end{array}$ \\
\hline \multicolumn{5}{|l|}{$14 \mathrm{~d}$} \\
\hline Control $(n=7)$ & $31 \pm 2$ & $183 \pm 9$ & $34316 \pm 1504$ & $46 \pm 4$ \\
\hline Gentamicin $(n=9)$ & $30 \pm 1$ & $185 \pm 6$ & $25220 \pm 2182^{*}$ & $41 \pm 5$ \\
\hline \multicolumn{5}{|l|}{$21 \mathrm{~d}$} \\
\hline Control $(n=6)$ & $51 \pm 2$ & $306 \pm 15$ & $35772 \pm 495$ & $223 \pm 39$ \\
\hline Gentamicin $(n=5)$ & $48 \pm 3$ & $290 \pm 17$ & $27427 \pm 2263^{*}$ & $180 \pm 38$ \\
\hline \multicolumn{5}{|l|}{$28 \mathrm{~d}$} \\
\hline Control $(n=6)$ & $77 \pm 2$ & $423 \pm 15$ & $35245 \pm 1088$ & $405 \pm 24$ \\
\hline Gentamicin $(n=8)$ & $81 \pm 3$ & $413 \pm 17$ & $29200 \pm 604 \dagger$ & $488 \pm 16$ \\
\hline \multicolumn{5}{|l|}{$3 \mathrm{mo}$} \\
\hline Control $(n=5)$ & $380 \pm 15$ & $1261 \pm 52$ & $35300 \pm 696$ & $1415 \pm 81$ \\
\hline Gentamicin $(n=5)$ & $386 \pm 8$ & $1382 \pm 52$ & $29080 \pm 482 \dagger$ & $1587 \pm 105$ \\
\hline \multicolumn{5}{|l|}{$6 \mathrm{mo}$} \\
\hline Control $(n=5)$ & $505 \pm 9$ & $1478 \pm 113$ & $34963 \pm 1188$ & $1811 \pm 28$ \\
\hline Gentamicin $(n=5)$ & $503 \pm 9$ & $1471 \pm 76$ & $29056 \pm 857^{*}$ & $1589 \pm 69^{*}$ \\
\hline \multicolumn{5}{|l|}{9 mo } \\
\hline Control $(n=6)$ & $586 \pm 24$ & $1739 \pm 66$ & $35827 \pm 905$ & $2021 \pm 100$ \\
\hline Gentamicin $(n=6)$ & $612 \pm 49$ & $1750 \pm 107$ & $27869 \pm 1342 \dagger$ & $1830 \pm 185$ \\
\hline \multicolumn{5}{|l|}{$12 \mathrm{mo}$} \\
\hline Control $(n=5)$ & $675 \pm 22$ & $1919 \pm 93$ & $37287 \pm 652$ & $2341 \pm 129$ \\
\hline Gentamicin $(n=7)$ & $670 \pm 47$ & $2178 \pm 241$ & $28250 \pm 720 \dagger$ & $1899 \pm 191$ \\
\hline
\end{tabular}

$* p<0.01$ compared with control value.

$\dagger p<0.001$ compared with control value.

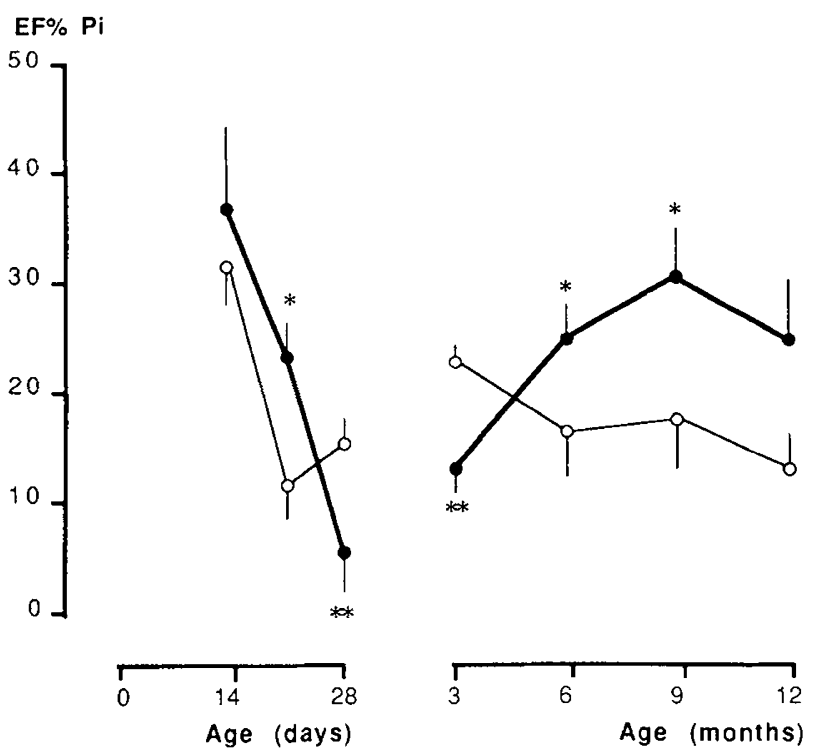

Fig. 1. Fractional excretion of phosphate in rats born of control mothers (open circles) and gentamicin-treated mothers (circles). ${ }^{*}$ and ${ }^{* *}, p<0.05$ and $p<0.01$ compared with controls.

cantly larger in rats born of gentamicin-treated mothers than in controls (Fig. 2). This was true for both deep and superficial nephrons, except in the 28-d-old animals of the gentamicin group, in which growth of the deep nephrons appeared to stop for awhile. In both nephron populations, compensatory hypertrophy reached its maximum before the age of $14 \mathrm{~d}$, after which glomerular growth was the same in the gentamicin and control groups. Like glomerular volume, proximal tubular length, measured in 14-d-old rats after microdissection, was significantly greater in animals born of gentamicin-treated mothers than in controls, both in superficial nephrons $(3.11 \pm 0.11 \mathrm{~mm}, n=54$, versus $2.41 \pm 0.09 \mathrm{~mm}, n=42, p<0.001$ ) and in deep nephrons ( $3.90 \pm 0.18 \mathrm{~mm}, n=54$, versus $2.95 \pm 0.09 \mathrm{~mm}, n=42, p<$ $0.001)$.

As already reported in a previous series of rats born of genta-
Table 2. Proteinuria in rats born of control and gentamicintreated mothers

\begin{tabular}{cc}
$\begin{array}{c}\text { Age and } \\
\text { treatment group }\end{array}$ & $\begin{array}{c}\text { Proteinuria } \\
(\mathrm{mg} / \mathrm{d})\end{array}$ \\
\hline 3 mo & $25.6 \pm 2.0$ \\
Control $(n=5)$ & $14.3 \pm 2.0^{*}$ \\
Gentamicin $(n=5)$ & $19.6 \pm 3.9$ \\
6 mo & $18.9 \pm 2.9$ \\
Control $(n=5)$ & $37.5 \pm 7.8$ \\
Gentamicin $(n=5)$ & $59.7 \pm 9.9$ \\
9 mo & $37.8 \pm 11.0$ \\
Control $(n=6)$ & $142.0 \pm 26.6 \dagger$ \\
Gentamicin $(n=6)$ & \\
12 mo & \\
Control $(n=5)$ & Gentamicin $(n=7)$ \\
\hline
\end{tabular}

$* p<0.01$ compared with control value.

$\dagger p<0.001$ compared with control value.

micin-treated mothers (3), the only damage visible by light microscopy in 14-d-old animals was in the proximal tubules. It included focal loss of brush border microvilli, prominent vacuolization, and cellular debris in the tubular lumen. The same type of lesions were still present at d 21 . On d 28 , glomeruli were still normal in appearance, and no injury was seen in the tubules. However, from 3 mo onward, glomerular and tubular damage was observed. The histologic quantification of the glomerular lesions in the animals issued from gentamicin-treated mothers revealed that, as early as $3 \mathrm{mo}, 41 \%$ of the juxtamedullary glomeruli exhibited grade 2 lesions (versus $23 \%$ in the control group). The extent of this lesion, which can be considered as a presclerosis step, slightly increased up to 24 mo to reach $53 \%$ of the juxtamedullary nephrons. As shown in Figure $3 \mathrm{~A}$, a concomitant drastic increase in the appearance of glomerulosclerosis was observed, which involved $18 \%$ of the deep nephron population at $12 \mathrm{mo}$ and nearly $40 \%$ at $24 \mathrm{mo}$, whereas these percentages were only 5.5 and $21 \%$, respectively, in control animals of corresponding ages. Illustration of glomerulosclerosis occuring in a 12-mo-old rat of the gentamicin group is given in Figure 4. With regard to the superficial nephrons, they were less damaged 

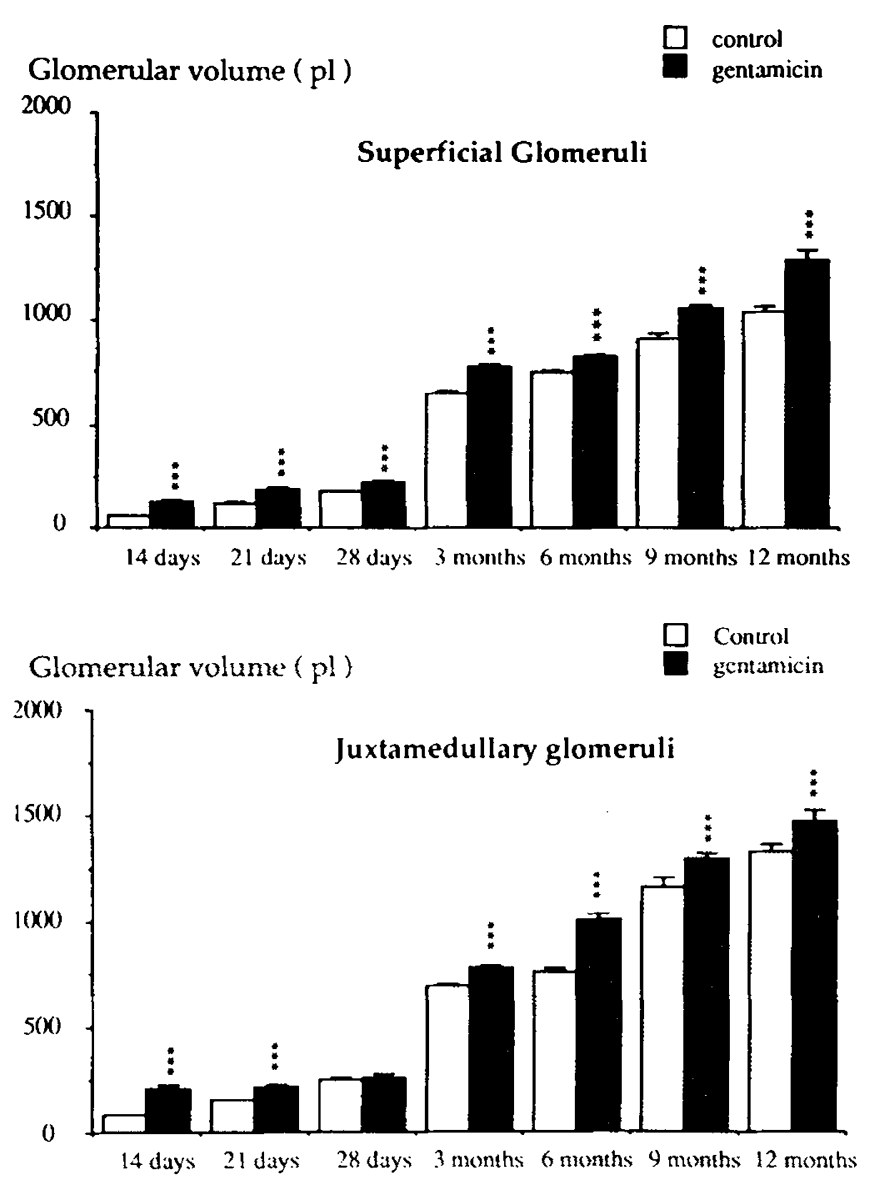

Fig. 2. Glomerular volume of superficial and juxtamedullary nephrons in rats born of control mothers (open bars) and gentamicin-treated mothers (solid bars). ${ }^{* * *}, p<0.001$ compared with controls.

than the juxtamedullary nephrons. As shown in Figure $3 A$, their sclerotic lesions were of the same magnitude in both groups. Nevertheless, from 6 mo onward, the percentage of glomeruli with presclerotic lesions (grade 2) was higher in the gentamicin group than in the controls ( 39 versus $23 \%$ at 24 mo of age). In the three animals that did not develop oligonephronia despite in utero gentamicin exposure, the glomerular lesions were of the same magnitude as those of the controls.

Tubular damage was also observed in proximal tubular segments with differences between control and experimental animals up to 6 mo of age. In control animals, small cytoplasmic inclusions that stained bright red with Masson's trichrome were clearly visible under phase-contrast microscopy. They were transiently more numerous at $6 \mathrm{mo}$, as shown in Figure $3 B$. In the 3- and 6-mo-old animals of the gentamicin group, a considerable increase in the number and size of these inclusions was observed. In some cases, they occupied the entire height of the epithelial cells and were very prominent (Fig. 5). From 9 mo onward, no difference was found between the two groups. Examination of the three animals born of gentamicin-treated mothers without oligonephronia revealed at 3 or 6 mo a very large amount of cytoplasmic inclusions, as found for the other animals born with oligonephronia. Unusual colloid casts were observed in the lumen of the cortical collecting tubules and of the medullary ascending limb of Henle's loop of 6-mo-old rats of the gentamicin group. In 12- and 24-mo-old animals, numerous casts were localized in all the tubular segments throughout the entire kidney section. In control animals, a few casts appeared at 12 and 24 mo. Lastly, interstitial fibrosis with thickening of the tubular basement membrane was observed in 12-and 24-mo-old animals of the gentamicin group. It was the major histologic modification at 24 mo for the controls.

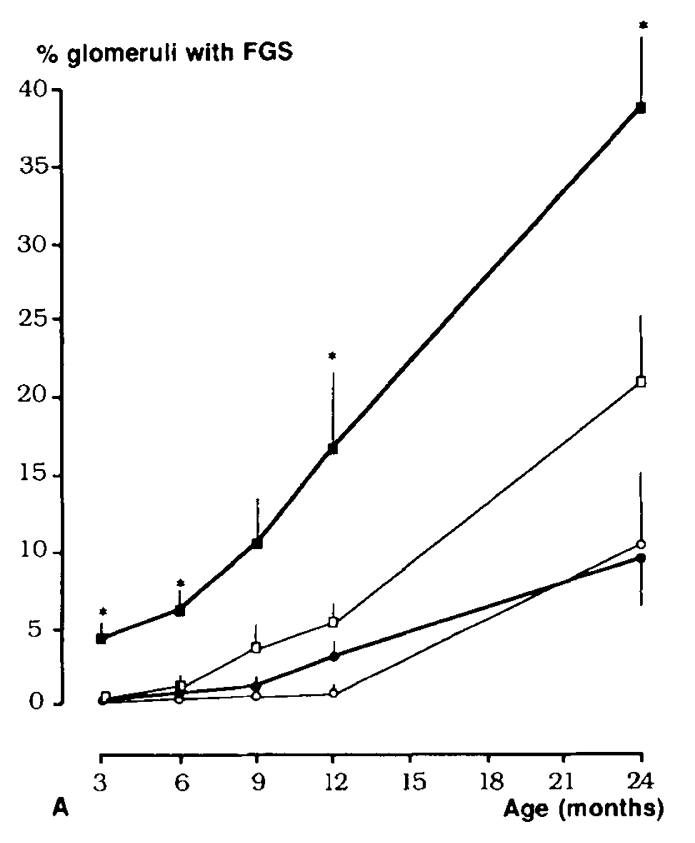

Proximal cytoplasmic inclusions

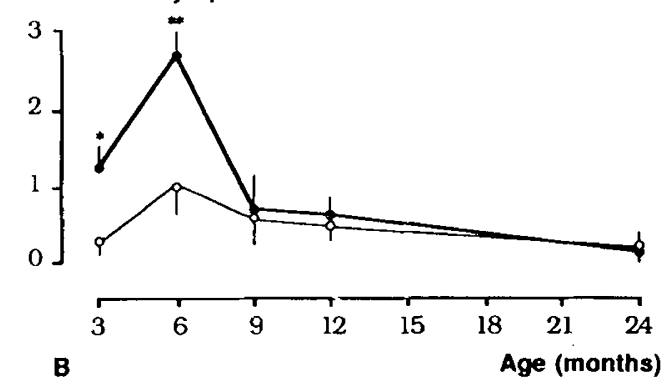

Fig. 3. Histologic score of renal lesions in rats born of control mothers (open symbols) and gentamicin-treated mothers (filled symbols). A, percent of juxtamedullary (squares) and superficial (circles) glomeruli with focal glomerular sclerosis $(F G S)$. B, score of proximal cytoplasmic inclusions, which were graded from 0 to 3 , as stated in the text. ${ }^{*}$ and **, $p<0.05$ and 0.01 compared with controls.

\section{DISCUSSION}

Renal response to oligonephronia acquired in utero in rats born of gentamicin-treated mothers. In rats born of gentamicin-treated mothers, the gentamicin present in kidney cells and the injuries it caused do not prevent renal growth and morphologic adaptation of the nephrons to their reduced number. Kaufman et al. (25) showed that the larger the nephron deficit, the greater the compensatory hypertrophy. Although in the present study the deficit in nephron mass did not exceed $20 \%$, the mean glomerular volume was considerably larger than in the controls within $14 \mathrm{~d}$ of birth. It is remarkable that the nephron loss was amply and rapidly compensated. It is possible that the nephrons most affected by the intracellular accumulation of gentamicin ceased to function, thus enlarging the reduction of the renal mass acquired in utero. In that case, however, one would have expected to find atrophy rather than hypertrophy in the fraction of nonfunctioning nephrons, and, therefore, greater heterogeneity of nephron size in the gentamicin group than in the controls, as observed in chronic kidney disease (13). The glomerular volume distribution depicted in Figure 6 shows that, for both the juxtamedullary and superficial nephron populations, virtually all the values in the gentamicin group were larger, although they were more scattered than in the controls. This clearly indicates that almost all of the glomeruli were hypertrophied, as is usual in response to partial 


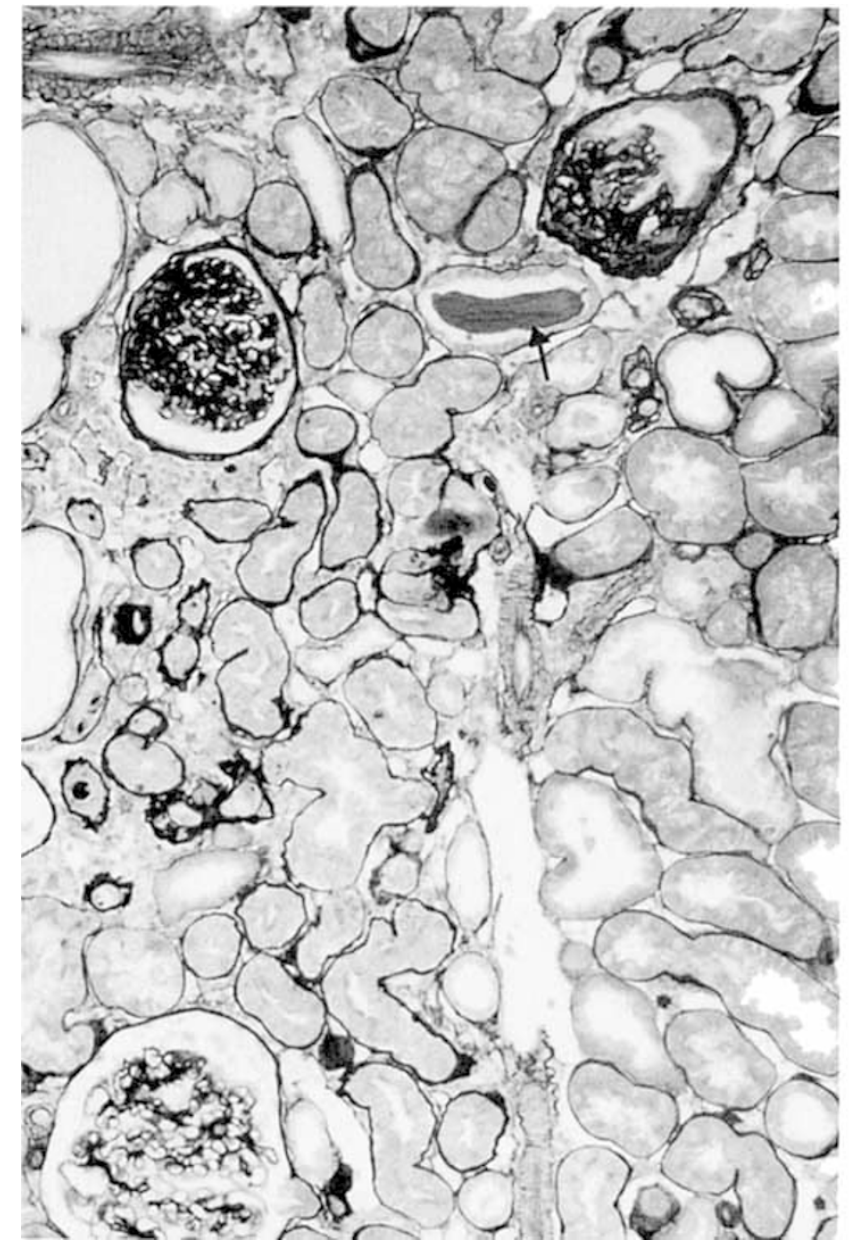

Fig. 4. Renal cortex of a 12-mo-old rat born of a gentamicin-treated mother. Glomeruli exhibit segmental glomerular sclerosis: mesangial sclerosis and adhesions between glomerular tuft and the Bowman's capsule are shown. Areas of fibroedematous interstitium containing atrophic tubular sections are visible. A cast is present in one tubular section (arrow). Jones' reticulin, $\times 120$.

nephrectomy in adult animals (for review see Ref. 13). Alternatively, such ample morphologic compensation in rats exposed to gentamicin in utero might be related to the fact that the reduction was acquired during fetal development. The compensatory response to unilateral nephrectomy has been reported to be greater when renal mass ablation is performed earlier (9-12). However, even in animals uninephrectomized during the first days after birth, the deficit was never shown to be entirely compensated for (12). Finally, because the gentamicin was still present in the renal tissue during the first postnatal weeks (3), we cannot exclude that the drug itself might have induced some changes in the glomerular ultrastructure. It has been reported that gentamicin administration could result in a decrease in the diameter and density of endothelial fenestrae, suggesting that the filtration rate per surface area was markedly reduced (26). However, these ultrastructural changes in permeability have not been always observed (27), despite the occurrence of a decrease in glomerular capillary ultrafiltration coefficient (28). The nephron mass reduction and the potential alterations in glomerular endothelial capillaries might have led to this glomerular hypertrophy, explaining the normal renal function measured.

The present data clearly show that, in rats born of gentamicintreated mothers, glomerular morphologic compensatory hypertrophy was accompanied by total glomerular functional compensation, which was already observed at $14 \mathrm{~d}$ and lasted until the age of $3 \mathrm{mo}$. A total compensation of glomerular function might not be achieved earlier because, as recently reported, exposure

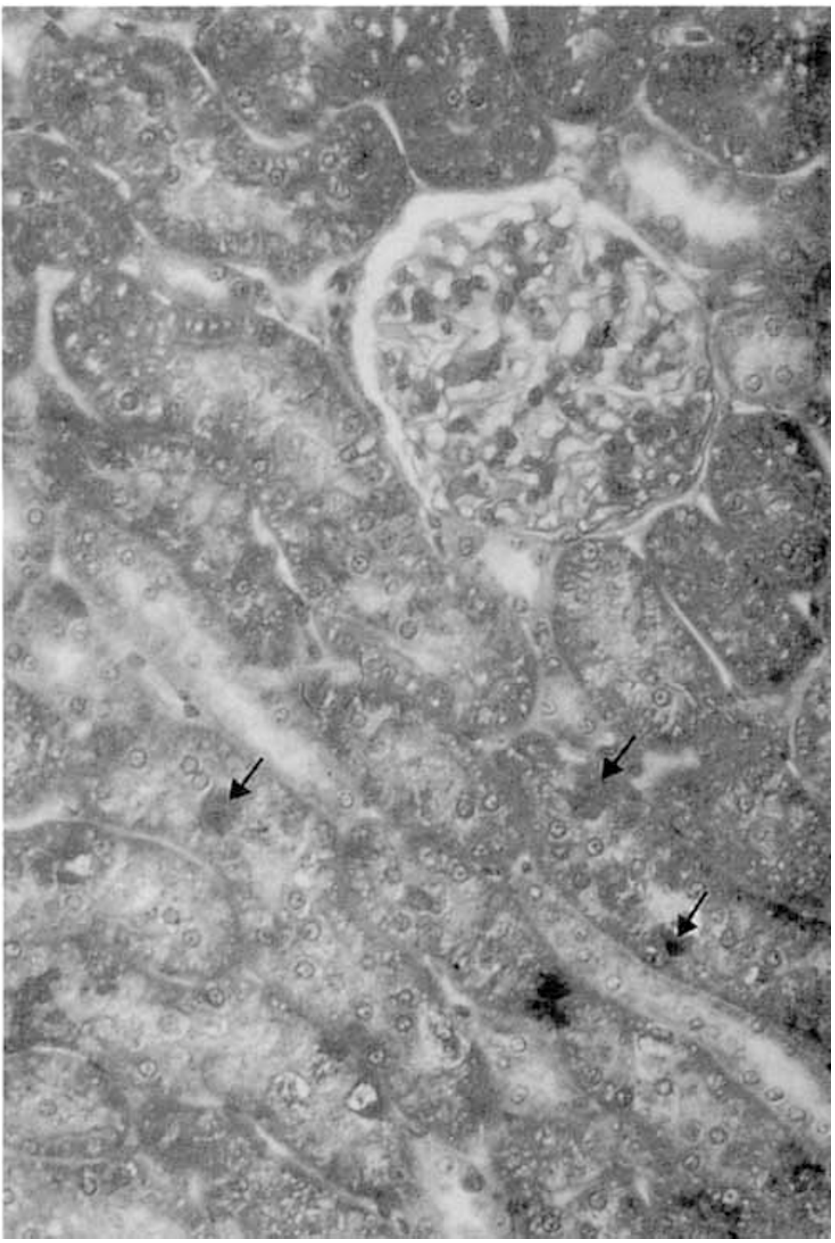

Fig. 5. Renal cortex of a 3-mo-old rat born of a gentamicin-treated mother showing an increase in the mesangial matrix of the glomerulus, and cytoplasmic inclusions (arrows) in proximal tubular cells. Masson's trichrome, $\times 250$.

in utero to the same dose of gentamicin as that used in the present study impairs glomerular function in the 1-d-old rat (5). In the present study, renal handling of water, total solutes, and phosphate indicated that tubular functions were also fully compensated as soon as d 14, and, subsequently, this remained true of the tubular functions studied except for phosphate transport, which on d 21 was still very low in the gentamicin group compared with the 21-d-old controls and did not significantly increase compared with 14-d-old animals of the same group. As previously shown, the phosphate transport system matures relatively late compared with other transport systems. In the rat, this system's affinity for phosphate cotransported with sodium doubles between postnatal d 14 and 21 (29). Any impairment of the brush border membrane caused by gentamicin during this period might have altered or simply retarded the late maturation process of the phosphate transport system, inasmuch as it is located in the apical membrane. In addition, the complete disappearance of brush border membrane in some tubular cells necessarily reduced the total number of carrier sites. It is worth noting that in 28-d-old animals whose kidney was free of visible gentamicininduced damage, at least when viewed at the light microscopy level, the phosphate transport capacity reached the value observed in 21 -d-old controls.

Long-term consequences of the nephrons' adaptation to their reduced number in rats exposed to gentamicin in utero. The present data clearly show that development of spontaneous chronic progressive nephrosis with increasing glomerulosclerosis was accelerated in rats born of gentamicin-treated mothers. This renal disease, which is a common feature in the aging rat, affects 

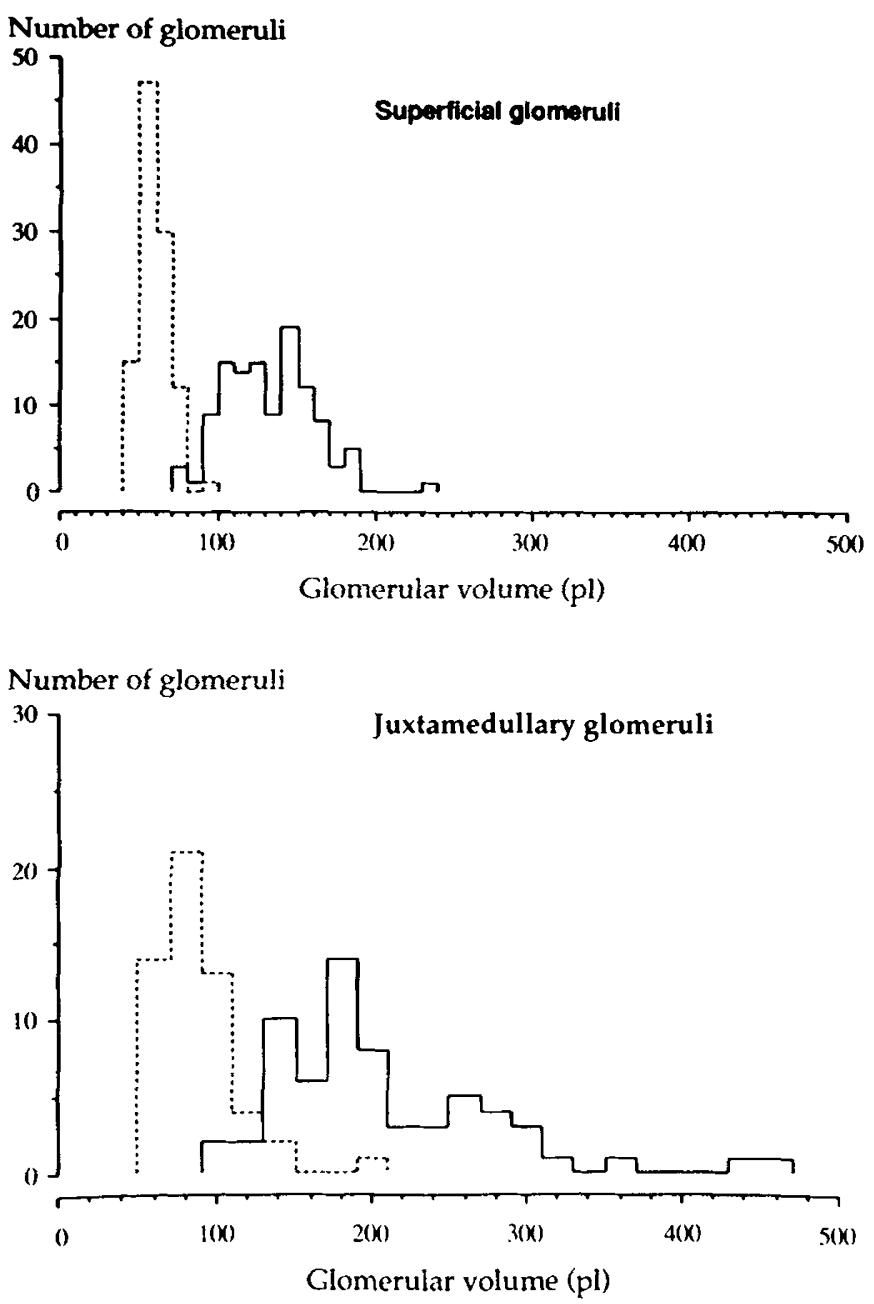

Fig. 6. Distribution of glomerular volumes of superficial and juxtamedullary nephrons in 14-d-old rats born of control mothers (dotted line) and gentamicin-treated mothers (solid line).

preferentially the male and has a higher incidence and severity for some strains such as the Sprague-Dawley (30-36).

It is now well established that progressive focal glomerular sclerosis is accelerated in response to the compensatory renal adaptation that follows nephron loss (for review see Ref. 13). There is thus good evidence that the early focal glomerular sclerosis we observed in the kidney of adult rats issued from gentamicin-treated mothers was due to their ample and rapid adaptation to the oligonephronia acquired in utero. This evidence is supported by the absence of early glomerular lesions in the three animals that did not exhibit oligonephronia although they were born of gentamicin-treated mothers. Consequently, an important feature that emerged from the present study is that a reduction of only $20 \%$ of nephron mass acquired in utero might accelerate the development of glomerular lesions in adult animals fed a standard protein diet. Similar findings arose from a recent study performed in rats born with mild oligonephronia of protein-deprived mothers (37). Although the present investigation did not concern the mechanism of the pathologic process of sclerosis caused by oligonephronia, it should be noted that no arterial hypertension was observed in rats issued from gentamicin-treated mothers. This correlation has previously been reported in some studies (38-40), but not confirmed in another (20). Furthermore, recently published data suggest that glomerular hypertrophy is associated with increased epithelial cells' detachment from the peripheral capillary wall, which can accelerate glomerular sclerosis, especially when nephron number is reduced (41). This might well explain the early development of glomerulosclerosis that we observed.
Surprisingly, there was a dissociation between glomerular injury and proteinuria in the 3- and 6-mo-old rats born of gentamicin-treated mothers. The presence of numerous cytoplasmic inclusions in the proximal tubular cells might have explained a lower proteinuria than expected in these animals. Cytoplasmic inclusions, which have been characterized to contain alpha 2 microglobulin, are naturally occuring in male albino rats $(35$, 42-45). However, their physiologic accumulation in kidneys of controls rats never develops as it did in 3- and 6-mo-old animals born of gentamicin-treated mothers. The pathologic exacerbation of this natural propensity has been also described in a hydrocarbon nephropathy model. In this model, increased reabsorption of alpha 2 microglobulin overwhelms proximal tubular cell capacity for its catabolism (46). The higher single nephron GFR we calculated at $3 \mathrm{mo}$, i.e. $54.0 \pm 3.6$ versus $39.5 \pm 1.9 \mathrm{~nL} / \mathrm{min}$ ( $p<0.01, n=5$ for both), without taking into account the glomeruli with grade 2 and grade 3 sclerosis, is consistent with this explanation. It is notable that the preferential accumulation of gentamicin into lysosomes, where it is known to alter catabolic activities and to induce myeloid body formation $(47,48)$, might considerably slow down the degradation of alpha 2 microglobulin and may also interfere with other low molecular weight proteins. This effect could explain why the three animals of the gentamicin group born without oligonephronia also exhibited large cytoplasmic inclusions.

In animals born of gentamicin-treated mothers, there was no drastic change in the GFR from 3 to $12 \mathrm{mo}$. However, the decline, although slight, was significant. This might indicate that the lesions observed in animals of the gentamicin group were severe enough for functional exclusion of some glomeruli and that no functional glomerular reserve remained in the other glomeruli to respond to this additional nephron loss. A recent study indicated that in rats about 1 mo-old the functional glomerular reserve disappeared when more than $75 \%$ of kidney tissue had been removed (49). On the other hand, it was suggested that no functional reserve remained in the kidney of rats undergoing uninephrectomy in early infancy that exhibited a much more pronounced response to nephron loss than control adults (20). However, protein loading experiments are necessary to precisely determine the ability of the present nephrons to respond to additional nephron loss in kidneys exhibiting an even smaller nephron deficit but one that was acquired in utero, i.e. earlier than in the above cases.

No significant progressive impairment of tubular functions was observed here until $1 \mathrm{y}$ in rats born of gentamicin-treated mothers, except for phosphate handling, which was found to be lower in 6- and 9-mo-old animals. Although no change in the plasma concentrations of calcium or phosphate was observed at any time, hyperparathyroidism cannot be excluded, as in other models of progressive renal disease $(50-52)$.

Finally, Bolton et al. (34) reported that despite the development of proteinuria and progressive histopathology aging rats die of nonrenal diseases. Nevertheless, we shall ponder the consequences of the important and rapid changes we observed, especially those concerning the glomerulosclerosis. The morphologic data obtained from 2 -yr-old animals born of gentamicintreated mothers raised the question of whether the few nephrons remaining intact where still able to maintain a normal renal function. Further studies are necessary to determine whether the rate at which glomerulosclerosis develops in rats presenting a $20 \%$ oligonephronia acquired in utero is life-shortening.

Acknowledgments. The authors thank Bernadette Nabarra for helpful discussions and advice in histopathology. We thank Martine Lanièce for technical assistance.

\section{REFERENCES}

1. Mallié JP, Gérard H, Gérard A 1984 Gentamicin administration to pregnant rats: effect on renal development in utero. Dev Pharmacol Ther 7(suppl1):89- 
2. Lelièvre-Pégorier M, Gilbert T, Sakly R, Meulemans A, Merlet-Bénichou C 1987 Effects of fetal exposure to gentamicin on the kidneys of young guineapigs. Antimicrob Agents Chemother 31:88-92

3. Gilbert T, Lelièvre-Pégorier M, Maliénou R, Meulemans A, Merlet-Bénichou C 1987 Effects of prenatal and postnatal exposure to gentamicin on renal differentiation in the rat. Toxicology 43:301-313

4. Gilbert T, Nabarra B, Merlet-Bénichou C 1988 Light and electron microscopic analysis of the kidney in newborn rats exposed to gentamicin in utero. Am J Pathol 130:33-43

5. Mallié JP, Coulon G, Billerey C, Faucourt A, Morin JP 1988 In utero aminoglycoside-induced nephrotoxicity in the rat. Kidney Int 33:36-44

6. Larsson L 1975 The ultrastructure of the developing proximal tubule in the rat kidney. J Ultrastruct Res 51:119-139

7. Bernard B, Garcia-Cazares SJ, Ballard CA, Thrupp LD, Mathies AW, Wehrle PF 1977 Tobramycin: maternal-fetal pharmacology. Antimicrob Agents Chemother 11:688-694

8. Bernard B, Abate M, Thielen PF, Attar H, Ballard CA, Wehrle PF 1977 Maternal-fetal pharmacological activity of amikacin. J Infect Dis 135:925932

9. Kaufman JM, Hardy R, Hayslett JP 1975 Age-dependent characteristics of compensatory renal growth. Kidney Int 8:21-26

10. Aschinberg LC, Koskimies O, Bernstein J, Nash M, Edelman Jr M, Spitzer A 1978 The influence of age on response to renal parenchymal loss. Yale J Biol Med 51:341-345

11. O'Donnell MP, Kasiske BL, Raij L, Keane WF 1985 Age is a determinant of the glomerular morphologic and functional responses to chronic nephron loss. J Lab Clin Med 3:308-313

12. Celsi G, Jakobsson B, Aperia A 1986 Influence of age on compensatory renal growth in rats. Pediatr Res 20:347-350

13. Brenner BM 1985 Nephron adaptation to renal injury or ablation. Am J Physiol 249:F324-F337

14. Habib R, Courtecuisse V, Mathieu H, Royer P 1962 Un type anatomo-clinique particulier d'insuffisance rénale chronique de l'enfant: l'hypoplasie oligoméganéphronique congénitale bilatérale. J Urol Nephrol 68:139-143

15. McGraw M, Poucell S, Sweet J, Baumal R 1984 The significance of focal segmental glomerulosclerosis in oligomeganephronia. Int J Pediatr Nephrol $5: 67-72$

16. Aperia A, Broberger O, Wilton P 1978 Renal functional adaptation in the remnant kidney in patients with renal agenesis and in patients nephrectomized in childhood. Acta Paediatr Scand 67:611-615

17. Thorner PS, Arbus GS, Celermajer DS, Baumal R 1984 Focal segment glomerulosclerosis and progressive renal failure associated with a unilateral kidney. Pediatrics 73:806-810

18. Kiprov DD, Colvin RB, McCluskey RT 1982 Focal and segmental glomerulosclerosis and proteinuria associated with unilateral renal agenesis. Lab Invest 46:275-281

19. Brenner BM, Garcia DL, Anderson S 1989 The renal abnormality in hypertension. A proposed defect in glomerular filtration surface area. In: Laragn $\mathrm{JH}$ Brenner BM (eds) Hypertension: Physiopathologie, Diagnosis, and Management. Raven Press Ltd., New York, pp 1151-1161

20. Celsi G, Bohman SO, Aperia A 1987 Development of focal glomerulosclerosis after unilateral nephrectomy in infant rats. Pediatr Nephrol 1:290-296

21. Chen PS, Torribara TY, Warner H 1964 Microdetermination of phosphorus. Anal Chem 28:1756

22. Lelièvre-Pégorier M, Sakly R, Meulemans A, Merlet-Bénichou C 1985 Kinetics of gentamicin in plasma of non-pregnant, pregnant, and fetal guinea-pigs and its distribution in fetal tissues. Antimicrob Agents Chemother 28:565569

23. Damadian RV, Shawayri E, Bricker NS 1965 On the existence of non-urine forming nephrons in the diseased kidney of the dog. J Lab Clin Med 65:2639

24. Merlet-Bénichou C, Pégorier M, Muffat-Joly M, Augeron C 1981 Functional and morphologic patterns of renal maturation in the developing guinea-pig. Am J Physiol 241:F618-F624

25. Kaufman JM, Siegel NJ, Hayslett JP 1975 Functional and hemodynamic adaptation to progressive renal ablation. Circ Res 36:286-293
26. Luft FC, Evan AP 1980 Comparative effects of tobramycin and gentamicin on glomerular ultrastructure. J Infect Dis 142:910-914

27. Bulger RE, Eknoyan G, Purcell DJ, Dobyan DC 1983 Endothelial characteristics of glomerular capillaries in normal mercuric chloride-induced and gentamicin-induced acute renal failure in the rat. J Clin Invest 72:128-141

28. Baylis C, Rennke HR, Brenner BM 1977 Mechanisms of the defect in glomerular ultrafiltration associated with gentamicin administration. Kidney Int 12:344-353

29. Lelièvre-Pégorier M, Jean T, Ripoche P, Poujeol P 1983 Transport of phosphate, D-glucose, and L-valine in newborn rat kidney brush border. Am $\mathrm{J}$ Physiol 245:F367-F373

30. Blatherwick NR, Medlar EM 1937 Chronic nephritis in rats fed high protein diets. Arch Intern Med 59:572-596

31. Gray JE, Weaver RN, Purmalis A 1974 Ultrastructural observations of chronic progressive nephrosis in the Sprague-Dawley rat. Vet Pathol 11:153-164

32. Couser WG, Stilmant MM 1975 Messangial lesions and focal glomerular sclerosis in the aging rat. Lab Invest 33:491-501

33. Elema JD, Arends A 1975 Focal and segmental glomerular hyalinosis and sclerosis in the rat. Lab Invest 33:554-56

34. Bolton WK, Benton FR, Maclay JG, Sturgill BC 1976 Spontaneous glomerular sclerosis in aging Sprague-Dawley rats. I. Lesions associated with messangial IgM deposits. Am J Pathol 85:277-302

35. Peter CP, Burek JD, Van Zwieten MJ 1986 Spontaneous nephropathies in rats. Toxicol Pathol 14:91-100

36. Burek JD, Duprat P, Owen R, Peter CP, Van Zwieten MJ 1988 Spontaneous renal disease in laboratory animals. Int Rev Exp Pathol 30:231-319

37. Gilbert T, Lelièvre-Pégorier M, Merlet-Bénichou C 1990 Glomerular damage in adult rats born with mild oligonephronia of protein-derived mothers. $J$ Am Soc Nephrol 1:629(abstr)

38. Morrison AB 1966 Experimental chronic renal insufficiency. Methods Achiev Exp Pathol 1:455-475

39. Purkerson ML, Hoffsten PE, Klahr S 1976 Pathogenesis of glomerulopathy associated with renal infarction in rats. Kidney Int 9:407-417

40. Hakim RM, Goldszer RC, Brenner BM 1984 Hypertension and proteinuria: long term sequelae of uninephrectomy in humans. Kidney Int 25:930-936

41. Miller PL, Scholey JW, Rennke HJ, Meyer TW 1990 Glomerular hypertrophy aggravates epithelial cell injury in nephrotic rats. J Clin Invest 85:1119-1126

42. Logothetopoulos J, Weinbren K 1955 Naturally occuring protein droplets in the proximal tubule of the rat's kidney. Br J Exp Pathol 36:402-406

43. Maunsbach AB 1966 Electron microscopy observations of cytoplasmic bodies with crystalline patterns in rat kidney proximal tubule cells. $J$ Ultrastruct Res 14:167-189

44. Roy AK, Raber DL 1966 Immunofluorescence localization of alpha 2 microglobulin in the hepatic and renal tissues of rat. J Histochem Cytochem 20:89-96

45. Kanerva RL, Ridder GM, Stone LC, Alden CL 1987 Characterization of spontaneous and decalin-induced hyaline droplets in kidneys of adult male rats. Food Chem Toxicol 25:63-82

46. Alden CL 1986 A review of unique male rat hydrocarbon nephropathy. Toxicol Pathol 14:109-111

47. Aubert-Tulkens G, Van Hoof F, Tulkens PM 1979 Gentamicin induced lysosomal phospholipidosis in cultured rat fibroblasts. Lab Invest 40:481491

48. Morin JP, Viotte G, Vandewalle A, Van Hoof F, Tulkens P, Fillastre JP 1980 Gentamicin induced nephrotoxicity: a cell biology approach. Kidney Int 18:583-590

49. Laouari D, Burtin M, Kindermans C, Kleinknecth C, Broyer M 1987 Evaluation of renal ablation causing functional reserve loss in rats fed low or high protein diet. Proceedings of the 10th International Congress on Nephrology, London, 505A(abstr)

50. Goldman R, Bassett SH 1954 Phosphorus excretion in renal failure. J Clin Invest 33:1623-1628

51. Slatopolsky E, Fradowska L, Kashemsant C, Keltner R, Manley C, Bricker NS 1966 The control of Pi excretion in uremia. J Clin Invest 33:672-677

52. Caverzasio J, Gloor HJ, Fleisch H, Bonjour JP 1982 Parathyroid hormoneindependent adaptation of the renal handling of phosphate in response to renal mass reduction. Kidney Int 21:471-476 